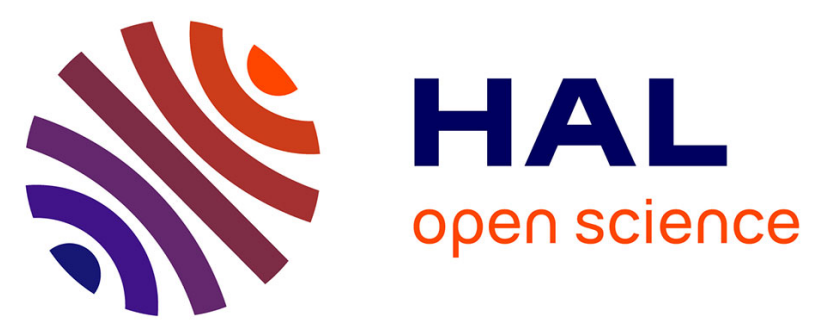

\title{
Utility detection and positioning on the urban site Sense-City using Ground-Penetrating Radar systems
}

Florence Sagnard, Christophe Norgeot, Xavier Derobert, Vincent Baltazart, Erick Merliot, François Derkx, Bérengère Lebental

\section{- To cite this version:}

Florence Sagnard, Christophe Norgeot, Xavier Derobert, Vincent Baltazart, Erick Merliot, et al.. Utility detection and positioning on the urban site Sense-City using Ground-Penetrating Radar systems. Measurement - Journal of the International Measurement Confederation (IMEKO), 2016, 88, pp.318-330. 10.1016/j.measurement.2016.03.044 . hal-01592975

\section{HAL Id: hal-01592975 \\ https://hal.science/hal-01592975}

Submitted on 3 Oct 2017

HAL is a multi-disciplinary open access archive for the deposit and dissemination of scientific research documents, whether they are published or not. The documents may come from teaching and research institutions in France or abroad, or from public or private research centers.
L'archive ouverte pluridisciplinaire HAL, est destinée au dépôt et à la diffusion de documents scientifiques de niveau recherche, publiés ou non, émanant des établissements d'enseignement et de recherche français ou étrangers, des laboratoires publics ou privés. 


\section{Utility detection and positioning on the urban site Sense-City using Ground-Penetrating Radar systems}

Florence Sagnard ${ }^{1}$, Christophe Norgeot ${ }^{2}$, Xavier Derobert ${ }^{1}$, Vincent Baltazart ${ }^{1}$, Erick Merliot ${ }^{1}$, François Derkx ${ }^{1}$, Bérengère Lebenta ${ }^{1}$

${ }^{1}$ University Paris-Est, IFSTTAR, 14-20, Bd Newton, 77420 Champs-sur-Marne, France

${ }^{2}$ MDS, 24, place Charles Fillion, 75017 Paris, France

\section{Abstract}

\section{Introduction}

The scale model Sense-City is an equipment of excellence for the Future Investment Program in the period 2011-2019 supported by University Paris-Est. It is a realistic mini-city demonstrator in the open air that is made of urban innovations focused on instrumented habitat and intelligent road. In a first time, a preliminary version has been built for test measurements such as visualized in Figure 1, and it will be rebuilt at the end of 2016 on a nearby field. The new version will be enlarged and enclosed in a mobile climatic chamber. At present, a part of the test site presented in Figures $2 \mathrm{a}$ and $2 \mathrm{~b}$ is made of a circular stretch of road where ten aligned utilities (pipes and blades) dielectric or conductive have been buried at depths ranging from 14.5 to $64.5 \mathrm{~cm}$. Before the site construction, the ground has been excavated as it is near a new building; thus, the ground has a multilayered structure that has significant dielectric contrasts as will be revealed by GPR measurements, that is quite interesting for research. The test-site Sense-City offers a real opportunity to study, in a controlled environment, the detection ability of the GPR technology and to interpret data using signal processing since laboratory sites are often costly and not easy to build.

The site has emerged in the context of the increasing demand for the non destructive mapping of underground utilities characterized by varied size and functions mainly in urban zones where networks are becoming denser. Since this application is recent, there is a need for GPR imaging technique to be evaluated considering several parameters associated with the radar system, the objects and the underground. The site is incorporated in the activities of COST TU1208 and is opened to academic and commercial contributors who want to test their equipments or post-treatments. It includes two distinct zones, one with buried pipes, and the other with buried blades; the objects are compared to usually of relative small lateral dimension (less than $15 \mathrm{~cm}$ ). The zone of buried pipes has proved to be a complex subsurface structure, thus this paper is focused on measurements in this zone based on several parameters: GPR time or frequency systems, operating frequency, dielectric contrast of the objects (air filled or water filled), and polarization. In this context, we have initiated a first measurement campaign of profile across the several buried pipes using different ground coupled radars (GSSI SIR 3000, SIR 4000 and a SFCW made of a pair of bowtie slot antennas conceived in our laboratory) at frequencies ranging from $300 \mathrm{MHz}$ to $1.6 \mathrm{GHz}$. The influence of the radar central frequency on the detection of the hyperbola signature of buried 
dielectric or conductive objects appears a main concern in this work as the multilayered structure of the soil has quite different values of real permittivities ranging from 4 to 35 , and the objects made of metal or dielectric (PVC) show different dielectric contrast with the soil; moreover, the PVC pipes can be filled with a liquid to bring an additional dielectric parameter in the site. As the dielectric characteristics of the soil layers itself is not a priori known, we have made preliminary measurements on a zone apart without objects to estimate the real permittivity of each layer and the main number of layers. This eases to better interpret profiles without and with buried objects where interactions with the surrounding medium exist. The profile measurements presented in this work highlights the potential of this laboratory site for GPR experiments and in the developments of signal processing techniques to extract quantitative information.

\section{The test site Sense-City}

The GPR test site, presented in Figure 1, has been built in the end of the test site Sense-City on a soil that has been preliminary excavated and rebuilt during the construction of the new IFSTTAR building. In the zone dedicated to object detection such as visualized in Figures 2a, $2 \mathrm{~b}$, and $2 \mathrm{c}$, ten trenches with width $30 \mathrm{~cm}$ and length $4 \mathrm{~m}$ have been dug. They have been separated by a distance of $40 \mathrm{~cm}$. When the trenches have been dug, we have found an interesting soil for research made of multilayers (four main layers) with a geotextile layer at the depth close to $30 \mathrm{~cm}$ under the soil surface (see Figure $3 \mathrm{a}$ ). On the soil surface an asphalt layer of $4.5 \mathrm{~cm}$ has been deposited and a circular road has been designed (see Figures $2 \mathrm{a}$ and $2 b$ ). The soil has been excavated to a maximum depth of $60 \mathrm{~cm}$; each buried utility has been positioned in the middle of its corresponding $30 \mathrm{~cm}$ width trench and at a predefined depth according to the scheme of Figure 3c. The second layer which was delimiting the initial surface is a dense and hard material $8 \mathrm{~cm}$ thick made of aggregate cement. The composition of the natural soil is not known, but it has appeared quite wet that explains the presence of a geotextile that aims to reduce the ascent of water in the shallow depth. After the excavation, the trenches have been filled with a soil made of fine elements (without gravels) usually used for urban utilities and it has been compacted, thus it must be noticed that the backfill soil is different from the natural soil. The buried objects are either pipes or blades as shown in Figure $3 \mathrm{~b}$; they are either dielectric or conductive. The pipes are either made of PVC (diameter $6.3 \mathrm{~cm}$ ) or a conductor (diameter $6 \mathrm{~cm}$ ), and the blades are either made of a polyurethane foam (thickness $2 \mathrm{~cm}$, height $10 \mathrm{~cm}$ ) or conductor (thickness $1 \mathrm{~cm}$, height $5 \mathrm{~cm}$ ) such as presented in Figure 3b. This first characterization mainly concerns pipe measurements as a cylinder represents a canonical object to obtain basic understanding of polarization phenomena.

First profile measurements have been made to characterize the susurface using the Fixed Offset Method (FOM). The radar GSSI SIR 3000 has been used with two pairs of antennas operating at the central frequencies 500 and $900 \mathrm{MHz}$ in a zone without objects. Raw radargrams (without time zero correction and clutter removal) presented in Figures $4 \mathrm{a}$ and $4 \mathrm{~b}$ show a soil made of marked four layers corresponding to asphalt (layer 1), aggregate cement (layer 2), a natural soil (layer 3), and a wetter natural soil (layer 4) located under the 
geotextile. A layer (layer 3b) of natural soil under the aggregate cement appears visible in this zone of the site and it a priori corresponds to a compacted layer of natural soil; this layer will not be observed in the zone with the trenches because the soil has been excavated. At both frequencies, the radargrams show diffractors in the natural soil that correspond to stones randomly distributed. At $500 \mathrm{MHz}$, the image appears more blurred and the interface responses less defined compared to $900 \mathrm{MHz}$, because the wavelength in the soil is larger. Assuming a mean real permittivity of 12.7 , the half wavelength is estimated to 8.4 at $500 \mathrm{MHz}$ and to 4.6 at $900 \mathrm{MHz}$. Thus, from the higher resolution radargram at $900 \mathrm{MHz}$, we

$$
\varepsilon^{\prime}
$$

have estimated the real permittivities since we have an a priori knowledge of the thickness $h$

of each layer from the construction phase. The back and forth propagation time is expressed commonly as follows:

$$
\left.\begin{array}{l}
t_{B F}=\frac{2 h}{v} \\
v \approx \frac{c}{\sqrt{\varepsilon^{\prime}}}\left(\varepsilon^{\prime \prime} \ll<\varepsilon^{\prime}\right)
\end{array}\right\} \Rightarrow \varepsilon^{\prime}=\left(\frac{t_{B F} c}{2 h}\right)^{2}
$$

According to Figure $4 \mathrm{~b}$, the real permittivity estimations of the soil layers are the following:

$$
\begin{array}{cl}
\text { asphalt (layer 1) } & (0.64 \mathrm{~ns}) \text {, aggregate cement (layer 2) } \\
\varepsilon_{3}{ }^{\prime}=34 & \varepsilon_{2}{ }^{\prime}=7.7
\end{array} \quad \text { (1.4 ns), natural soil }
$$

(mean of layers $3 \mathrm{~b}$ and 3$) \quad(8.5 \mathrm{~ns})$. It must be noticed that the real permittivity of the natural soil is quite high leading to important contrast between layers. Such a high permittivity is caused by the presence of water. This permittivity value will be confirmed afterwards by migration results.

\section{GPR systems}

We had the opportunity to use three different GPR systems to acquire profiles of the underground of the novel test site. Firstly, commercial time domain radars GSSI SIR 3000 and SIR 4000 have been used. The SIR 3000 has been equipped alternatively with three pairs of antennas centered at 500, 900 and $1600 \mathrm{MHz}$; the distance steps were 4, 7 and $4 \mathrm{~mm}$. The SIR 4000 incorporates a double frequency antenna system at 300 and $800 \mathrm{MHz}$ that collects data rapidly at one frequency at a time so that when walking the measurement point is considered at the same location for both frequencies. For both GPR systems the polarization of the electric field is perpendicular (TM polarization) to the linear radar displacement and thus parallel to the trenches (pipes). The antenna box have the following dimensions: at $500 \mathrm{MHz}$

$$
30 \times 30 \mathrm{~cm}^{2}
$$

$\mathrm{xx}$, at 300 and $800 \mathrm{MHz}$

$$
18 \times 33 \mathrm{~cm}^{2}
$$

(21 cm offset at $300 \mathrm{MHz}$ and $8 \mathrm{~cm}$ offset at $800 \mathrm{MHz}$ ), at

$900 \mathrm{MHz}$

and at $1500 \mathrm{MHz}$

$$
10 \times 15 \mathrm{~cm}^{2}
$$


observation has been defined for each frequency to better visualized the deep hyperbolas. The observation time appears more limited in the SIR 3000 as the system used is not recent.

Moreover, a step frequency continuous wave (SFCW) radar designed in our laboratory has been used. The system is composed of two shielded bowtie slot antennas with size $231 \times 362 \mathrm{~mm}^{2}$

that are connected via a $2 \mathrm{~m}$ length radiofrequency coaxial cable to a portable vector network analyzer (VNA) Anritsu MS 2026B to transmit and receive sinusoidal electromagnetic waves. As the antennas are independent of each other, it was possible to consider two antenna configurations mirror (co-polar) and end fire to study the polarization

effect on object detection. The measurement of the complex transmission coefficient ${ }_{21(f)}$ has been made in the frequency band $[0.05 ; 4] \mathrm{GHz}$ (1601 samples) with a distance step of 40 $\mathrm{mm}$. To obtain time domain data, an apodization of each trace has been made to smoothly extend the frequency band from 4 to $9 \mathrm{GHz}$. An excitation pulse has been added to select part of the spectrum measured and make comparisons with radargrams issued from the commercial GPR systems; the pulse has the shape of the first derivative of the Gaussian function. Such a pulse is defined as follows:

$$
S(t)=-a^{2} A t \exp \left(-a^{2} t^{2}\right)
$$

Where ${ }^{A}$ is the pulse amplitude, and ${ }^{a}$ the shape factor that determines the slope of the Gaussian pulse. In this work, we have considered the

$$
\tau=\frac{1}{\sqrt{2} a}
$$

parameter . The pulse spectrum is characterized by its peak

frequency ${ }^{f_{0}}$ and its bandwidth $\stackrel{\Delta f}{ }$ at $-3 d B$ such as:

$$
\left\{\begin{array}{l}
f_{0}=\frac{a \sqrt{2}}{2 \pi} \\
\Delta f=1.155 f_{0}=\frac{1.155}{T_{0}}
\end{array}\right.
$$

$T_{0}$

is the pulse duration.

As an illustration, Gaussian pulses associated with different central frequencies 500, 900 and $1500 \mathrm{MHz}$ have been plotted in Figures $5 \mathrm{a}$ and $5 \mathrm{~b}$ in the time and frequency domains. Their durations ${ }^{\Delta T}$ and bandwidths ${ }^{B W}$ at $-3 \mathrm{~dB}$ are the following: at $500 \mathrm{MHz}, \quad \Delta T=1.8 n s$ 


$$
\begin{aligned}
& B W=1000 \mathrm{MHz} \\
& B W=3000 \mathrm{MHz}
\end{aligned} \text {, at } 900 \mathrm{MHz}, \quad \text { and } \quad \text {, and at } 1500 \mathrm{MHz}, \quad \begin{aligned}
& \Delta T=0.6 \mathrm{~ns} \\
& \text { and }
\end{aligned}
$$

\section{Experimental results}

Before analyzing experimental radargrams, 3D FDTD simulations have been under the commercial software EMPIRE. Since the geometry of the bowtie slot antennas belonging to the SFCW radar are known, the GPR system in both configurations mirror (TE polarization) and end fire (TM polarization) has been modeled and simulated on a soil representing the soil of the experiments (see Figures 6a and $6 \mathrm{c}$ ). The soil modeled is made of a $4.5 \mathrm{~cm}$ thick

$$
\begin{aligned}
& \varepsilon_{1}^{\prime}=4 \quad \sigma_{1}=0.015 . m^{-1} \quad \varepsilon_{3}^{\prime}=10 \quad \sigma_{3}=0.015 . m^{-1} \\
& \varepsilon_{2}^{\prime}=5 \quad \sigma_{2}=0.01 S . m^{-1}
\end{aligned}
$$

trench ( , ) filled with a pipe buried at a depth of $15.5 \mathrm{~cm}$ under the asphalt layer. The pipe with diameter $6.4 \mathrm{~cm}$ is made of PVC and has been filled with air. The GPR system is supposed to move linearly with a $4 \mathrm{~cm}$ step distance perpendicular to the pipe axis. The excitation pulse is a Gaussian function with duration $0.5 \mathrm{~ns}$ and its spectrum is centered at the frequency $1 \mathrm{GHz}$ and extends to $3 \mathrm{GHz}$ at $-20 \mathrm{~dB}$ (see Figures $5 \mathrm{c}$ and 5c). The synthetic radargrams visualized in Figures $5 \mathrm{~b}$ and $5 \mathrm{~d}$ in the TE and TM polarizations respectively highlight that the TE polarization is best suited to detect an air filled pipe in a high dielectric soil. The arrival time difference estimated to $1.5 \mathrm{~ns}$ between the maximum of the hyperbola and horizontal strip associated to the upper layer leads to an estimated depth of $14.2 \mathrm{~cm}$ close to the initial value of $15.5 \mathrm{~cm}$.

Afterwards, a campaign of measurements has been led on the pipe zone of the test site Sense City. A section view of the pipe zone is presented in Figure 7 where it can be noticed that the depth range of the pipes is between 10 and $50 \mathrm{~cm}$ under the asphalt layer. All the pipes have similar diameters that are $6.3 \mathrm{~cm}$ in the case of PVC pipes, and $6 \mathrm{~cm}$ in the case of the metallic pipe. There is one metallic pipe buried at the depth of $20 \mathrm{~cm}$ (T3), and two close PVC pipes separated by a distance around $12 \mathrm{~cm}$ (T6). Only one pipe (T5) has been buried under the geotextile layer. All PVC pipes can be filled with water or another liquid to study the influence of their dielectric permittivity in the detection and the hyperbola signature.

Profiles in the pipe zone have been obtained along the same central line on the test site (see Figure 2b) using the three GPR systems: the SIR 3000, SFCW georadar, and the double frequencies SIR 4000. The PVC pipe in trench T5 has been firstly filled with air. At first, the SIR 300 system equipped with antenna pairs operating at frequencies 500,900 and $1500 \mathrm{MHz}$ has allowed to obtain the raw images (with only a linear time gain filter) presented in Figures $8 \mathrm{a}, 8 \mathrm{~b}$ and $8 \mathrm{c}$; the observation time has been preliminary defined to $15 \mathrm{~ns}$. In the radargrams 
no time zero corrections has been applied, to visualize all the propagating and reflecting waves. During the trench digging the aggregate cement layer (second layer) has to be broken and mainly removed, so this layer will be different from the layer measured without objects (see Figures $4 \mathrm{a}$ and $\mathrm{b}$ ). This layer has been mainly be replaced by the backfill soil which has served to fill the trenches. At the frequency $500 \mathrm{MHz}$ (sampling distance $4 \mathrm{~mm}$ ), the signatures of trenches T1, T2, T4 and T6 appear clearly visible such as visualized in Figure 8a. Trench T1 alone is detectable because of the permittivity contrast of the soil between the interior and the exterior. The hyperbola of the metallic pipe in T3 appears with a signature inverse as compared to the hyperbolas of PVC pipes. The hyperbolas of T4 and T5 are not clearly detected because the pipes are positioned deeper as compared to the others. T3 hyperbola appears quite blurred, and both pipes in T6 can be distinguished and appear at a close time as in the case of the conductive pipe in T3. The responses of the two upper layers appear blurred and thick because the duration of the pulse exceeds the propagation time in them. Nevertheless, we can estimate the mean soil permittivity under the asphalt layer that gives the value 15.8. At the frequency $900 \mathrm{MHz}$ (sampling distance $7.5 \mathrm{~mm}$ ), hyperbola signatures of trenches T1, T2, T3 and T6 appear clearly visible such as presented in Figure 8b. Because the time resolution is higher, the geotextile layer appears visible around the time 12.1 ns. At this higher frequency, we can estimate the real permittivities of the first 3 layers according to relation 1: asphalt $\varepsilon_{1}^{\prime}=4$, backfill soil $\varepsilon_{2}^{\prime}=6.9$, and natural soil $\varepsilon_{3}^{\prime}=36$. At the frequency $1500 \mathrm{MHz}$ (see Figure 8c), multiple reflections occur in the two upper layers, and we notice all trenches signatures. In general, the pipes show more attenuated hyperbolas than at frequency $900 \mathrm{MHz}$, but the pipe signatures appear already visible.

Measurements using the SFCW georadar system (sampling distance $40 \mathrm{~mm}$ ) have been made manually according to procedures shown in Figures $9 \mathrm{a}$ and $9 \mathrm{~b}$ where two polarization configurations TE and TM have been proposed. No low pass and high pass filters and time zero correction have been applied here. The spectrum of synthetic pulses centered at frequencies 500, 900 and $1500 \mathrm{MHz}$ such as presented in Figure 5a have been multiplied to the frequency data measured to obtain time responses centered at a given frequency. A linear time gain (see Figure 10d) has been applied to the radargrams of Figures 10a, 10b, and 10c that are associated with the mirror configuration. These radargrams associated with the three mentioned frequencies give similar results compared to the radargrams issued from the SIR 3000 system concerning hyperbola detection and time differences. In general, the hyperbolas show there a larger curvature radius than in the radargrams obtained with the SIR 3000 because the bowtie slot antennas have a larger lateral dimension. The air filled pipe at depth $30 \mathrm{~cm}$ in T4 show here a detectable hyperbola signature at $900 \mathrm{MHz}$. However, the signature of trench T1 is not easily detectable, certainly because the distance step is not small enough. Afterwards, measurements have been made in the end fire configuration at the frequency $900 \mathrm{MHz}$ such as presented in Figure 11; the measurements have been made in two sequences that induces a vertical discontinuity in the radargram. In general, we remark that all the hyperbolas appear strongly attenuated and it will be interesting to insert in the future a dielectric liquid in the PVC pipes to study its polarization as a function of the orientation of the main electric field. 
Afterwards, water has been put into the PVC pipe of trench T5, and radar profiles have been obtained using the SIR 3000 system at frequencies 500 and $900 \mathrm{MHz}$. From Figures 12a and $12 \mathrm{~b}$ that pipe in T5 appears visible at both frequencies without sign inversion, and moustaches produced by the diffraction at the bottom edges of the trenches are visible at $500 \mathrm{MHz}$.

Finally, experimental profiles on the central line defined previously have been obtained using the double frequency SIR 4000 radar system (sampling distance $10 \mathrm{~mm}$ ). The excitation resembles to the first derivative of the Gaussian function as visualized in Figure 13a. A linear gain and low and high pass filters have been applied to the raw data. Comparing to previous radargrams acquired at the frequency $500 \mathrm{MHz}$, it appears difficult to visualize the pipe signatures in trenches T4 and T5 and in trench T1 without object (T5 has been water filled here). We remark that the arrival time differences between the object signatures and the upper layers are similar to those evaluated previously. The data have been migrated using the software RADAN that are presented in Figure 13b. The migration appears visually optimum for a real permittivity value of 12.75 . At $900 \mathrm{MHz}$, the profile gives the radargram in Figure 14a. As compared to the SIR 3000, the SIR 4000 allows to define more easily a time range adapted to the structure to be probed. Thus, at $900 \mathrm{MHz}$ all the object signatures appears clearly in the six trenches and a sign inversion is visible in the signature of the metallic pipe in T3. The migrated data leading to the radargram of Figure $14 \mathrm{~b}$ correspond to the previous real permittivity value that has is also considered optimum. This mean value corresponding to depths above the hyperbolas confirms that the natural soil has a permittivity close to 32 . Afterwards, a set of profiles $[-40 ;+60] \mathrm{cm}$ equidistant of $20 \mathrm{~cm}$ on both sides of the central lines at $900 \mathrm{MHz}$ have been measured to obtain a Cscan. All the Bscans have been migrated at a velocity associated with the permittivity 12.75 and a horizontal section from the surface has been lowered into the depth of the structure to highlight the depth of the buried objects. A section at a given position in depth has an amplitude map associated with upper and lower sections included in a $6 \mathrm{~cm}$ thickness. The depth zero is supposed here at the asphalt interface. The six sections visualized in Figures 15 and 16 correspond to the six trenches. The depths obtained are $15 \mathrm{~cm}, 21.8 \mathrm{~cm}, 23.6 \mathrm{~cm}, 24.8 \mathrm{~cm}, 33.4$ and $49.4 \mathrm{~cm}$ for the trenches T2, T6, T3, $\mathrm{T} 1, \mathrm{~T} 4$, and T5 respectively. These depth estimations confirm the theoretical values of the scheme in Figure 7. Moreover, we have noticed that in trenches T4 and T5 the pipes are not fully horizontal but slightly inclined.

\section{Conclusion}

The laboratory site Sense-City...

First measurements have been made in the blade zone but they have actually been analyzed in details.

\section{References}

[1] http://sense-city.ifsttar.fr/ 
[2] Proceedings of the General Meeting of COST Action TU1208, Rome (IT), 22-24 July 2013. http://www.cost.eu/domains_actions/tud/Actions/TU1208

[3] Andrea Benedetto, Lara Pajewski, "Civil engineering applications of ground penetrating radar", Ed. Springer 2015

[4] W.M.A. Wan Hussin and M. Bashir Alhasanat, "The design of a GPR test site for underground utilities", PIERS Proceedings, Marrakesh, Marocco, March 20-23, 2011

[5] M. Metwaly, "Application of GPR technique for subsurface utility mapping: a case study from urban area of Holy Mecca, Saudi Arabia", Measurement, vol. 60, 2015, pp. 139-145

[6] S. Wazlan Wahab, "Assessing the condition of buried pipe using ground penetrating radar", Thesis, Master of Philosophy, University of Birmingham, Aug. 2013

[7] A.H. Abdelgwad, T.M. Said, A.M. Gody," Developing of a ground penetrating radar antenna for detecting water pollution in underground pipelines", Int. Journ. Microwave Applications, vol. 4, n. 1, Janv. Feb. 2015

[8] F. Sagnard, "Design of a compact ultra-wide band bow-tie slot antenna system for the evaluation of structural changes in civil engineering works", Progress in Electromagnetic Research, PIER B, vol. 58, 2014, pp. 181-191

[9] F. SAGNARD, and E. TEBCHRANY, "Using polarization diversity in the detection of small discontinuities by an ultra-wide band ground penetrating radar", Measurement, Vol. 61, Feb. 2015, pp. 129-141

[10] H. Sheng, P. Orlik, A.M. Haimovich, L.J. Cimini, and J. Zhang, "On the spectral and power requirements for ultra-wideband transmission", IEEE International Conference on communications (ICC'03), 2003

[11] S. J. Radzevicius, J.J. Daniels, Ground penetrating radar polarization and scattering from cylinders, J. Applied Geophys., 45 (2000) 111-125

\section{List of figures}

Figure 1: General view of the mini-city laboratory test Sense-City

Figure 2: Schemes of the GPR test site: (a) Top view with the coatings, (b) Top view without coatings including the trenches, (c) Picture of the trenches under construction

Figure 3: Schemes detailing the different components of the GPR site: (a) Structure of the subsurface, (b) geometries and dimensions of the buried objects, and (c) Distribution of the buried blades and pipes

Figure 4: Experimental radargrams (Bscans) of the subsurface without buried objects measured by the SIR 3000 system (linear gain and low and high pass filters applied): (a) at $500 \mathrm{MHz}$, and (b) at $900 \mathrm{MHz}(\mathrm{SIR} 3000)$

Figure 5: Pulse excitation signals used (1srt derivative of the Gaussian function) in time and frequency domains: $(a, b)$ in the SFCW radar, and $(c, d)$ in FDTD simulations under EMPIRE 
Figure 6: 3D full-wave FDTD simulations of the SFCW radar with a pair of bowtie slot antennas in the TE and TM polarizations: $(a, b)$ the corresponding geometry and the raw radargrams $(b, d)$

Figure 7: Section view of the pipe zone including the pipe positions and depths noticed during the site construction

Figure 8: Experimental radargrams (Bscans) associated with the central line profile of the pipe zone (air-filled in T5) measured by the SIR 3000 system (linear gain and low and high pass filters applied): (a) at $500 \mathrm{MHz}$, (b) $900 \mathrm{MHz}$, and (c) $1500 \mathrm{MHz}$

Figure 9: Pictures of both polarization configurations used with the SFCW radar: (a) TM polarization, and (b) TE polarization

Figure 10: Experimental radargrams (Bscans) associated with the central line profile of the pipe zone (air-filled pipe in T5) measured by the SFCW radar system in the mirror configuration (linear gain applied) presented in the time domain using synthetic Gaussian pulses centered at: (a) $500 \mathrm{MHz}$, (b) $900 \mathrm{MHz}$, and (c) $1500 \mathrm{MHz}$. (d) Curve of the linear gain versus time

Figure 11: Experimental radargrams (Bscans) associated with the central line profile of the pipe zone (air-filled pipe in T5) measured by the SFCW radar system in the end fire configuration (linear gain applied) using a synthetic Gaussian pulse centered at $900 \mathrm{MHz}$ (linear gain applied)

Figure 12: Experimental radargrams (Bscans) associated with the central line profile of the pipe zone (water-filled in T5) measured by the SIR 3000 system (linear gain and low and high pass filters applied) at: (a) $500 \mathrm{MHz}$, and (b) $900 \mathrm{MHz}$

Figure 13: Experimental radargrams (Bscans) associated with the central line profile of the pipe zone (water-filled in T5) measured by the SIR 4000 system (linear gain and low and high pass filters applied) at $300 \mathrm{MHz}$ : (a) raw data, and (b) migrated data $\left(\varepsilon^{\prime}=12.75\right)$

Figure 14: Experimental radargrams (Bscans) associated with the central line profile of the pipe zone (water-filled in T5) measured by the SIR 4000 system (linear gain and low and high pass filters applied) at $800 \mathrm{MHz}$ : (a) raw data, and (b) migrated data $\left(\varepsilon^{\prime}=12.75\right)$

Figure 15: Experimental 3D views of migrated data $\left(\varepsilon^{\prime}=12.75\right)$ at $900 \mathrm{MHz}$ measured by the SIR 4000 system at several depths: (a) $15 \mathrm{~cm}$, (b) $21.8 \mathrm{~cm}$, (c) $23.6 \mathrm{~cm}$, and (d) $24.8 \mathrm{~cm}$

Figure 16: Experimental 3D views of migrated data $\left(\varepsilon^{\prime}=12.75\right)$ at $900 \mathrm{MHz}$ measured by the SIR 4000 system at several depths: (e) $33.4 \mathrm{~cm}$, and (f) $49.4 \mathrm{~cm}$ 